\title{
Preliminary assessment of cephalopharyngeal skeleton length and body length of Hemipyrellia ligurriens (Wiedemann) (Diptera: Calliphoridae) larvae as potential parameters to estimate minimum post mortem interval
}

\author{
Puspa Eliza ${ }^{1}$ and Raja M. Zuha ${ }^{1,2^{*}}$
}

\begin{abstract}
Entomological evidence can be utilized in forensic investigation to estimate the elapsed time after death or minimum post mortem interval estimation $\left(\mathrm{PMI}_{\mathrm{min}}\right)$. This estimation is based on the age of dipterous specimens feeding on decomposing human tissues, which commonly refers to their larval body length. The objective of this research was to look for alternatives to larval body length which could be impaired by specimen handling and subsequently causing inaccuracy in $\mathrm{PMI}_{\min }$ estimation. In this research, development of forensic blow fly, Hemipyrellia ligurriens (Wiedemann) (Diptera: Calliphoridae), based on larval cephalopharyngeal skeleton length, was described for the first time. Development of $\mathrm{H}$. ligurriens was represented by body length and cephalopharyngeal skeleton consisting anterodorsal process to dorsal cornu (ADP-DC), anterodorsal process to ventral cornu (ADP-VC) and dorsal cornu to ventral cornu (DC-VC). The cephalopharyngeal skeletons proportionally developed with larval body development, but periods of plateau existed between 0 and $10 \mathrm{~h}$ and 24-30 h, suggesting ecdysis periods of larvae. Data measurements were more consistent in cephalopharyngeal skeleton length than in larval body length, and there were strong positive significant correlations, $r>0.85(p<0.05)$. These findings warranted further investigations to examine cephalopharyngeal skeleton as an alternative growth parameter to larval body length.
\end{abstract}

Keywords: Forensic entomology, Morphometric, Blowfly, Development

\section{Background}

In forensic entomology, estimation of minimum post mortem interval $\left(\mathrm{PMI}_{\mathrm{min}}\right)$ in death investigations is derived from the assessment of insects or arthropods that can be found feeding on decomposing human tissues. The evaluation of $\mathrm{PMI}_{\min }$ commonly refers to the age of the oldest dipterous larvae collected in forensic case based on their growth parameters such as body length, width (Day and Wallman 2006), weight (Wells and

\footnotetext{
* Correspondence: rmzuha@ukm.edu.my

${ }^{1}$ UKM Forensics, Faculty of Health Sciences, Basement One Tun Seri Lanang Library, Universiti Kebangsaan Malaysia, 43600 Bangi, Selangor, Malaysia ${ }^{2}$ Centre for Insect Systematics, Faculty of Science \& Technology, Universiti Kebangsaan Malaysia, 43600 Bangi, Selangor, Malaysia
}

LaMotte 1995) and larval stage development (Amendt et al. 2007). Since there is a gradual increase of larval length with time, it has been widely employed as a reference value to estimate its age and $\mathrm{PMI}_{\min }$ (Byrd and Castner 2010).

However, there are various factors that can affect larval length in $\mathrm{PMI}_{\text {min }}$ determination (Amendt et al. 2011). In forensic practice, it includes the method of killing and preserving the larvae that could cause a significant underestimation in the age values of the larvae (Tantawi and Greenberg 1993; Adams and Hall 2003), and thus, resulting inaccuracies in $\mathrm{PMI}_{\min }$ calculations. Moreover, handling of preservatives could also alter the conditions of larval specimens, such as colour changes 
and degradation of specimens' quality (Day and Wallman 2008; Rosilawati et al. 2014). This also includes storage periods in preservatives that affected larval body length and weight (Midgley and Villet 2009; Richards et al. 2013).

To obtain a more reliable growth parameter than larval body length, cephalopharyngeal skeleton length was proposed as an alternative growth parameter for $\mathrm{PMI}_{\text {min }}$ estimation (Rabbani and Zuha 2017). By using traditional morphometric analysis, measurements were obtained from landmarks distances of cephalopharyngeal skeletons. This technique is the basis to geometric morphometrics which provides ideal tools in shape analysis to discriminate insect species or sexual dimorphism (Zelditch et al. 2012; Nuñez-Rodríguez and Liria 2017). Although there are various applications that can be found in morphometric analysis regarding shapes and growth of biological organisms (Bookstein 1982; Strauss and Bookstein 1982; Marcus 1988; James Rohlf and Marcus 1993), the methodology being used in this present research was only limited to measuring distances between landmarks (Daly 1985). Furthermore, information regarding development of calliphorid larvae based on cephalopharyngeal skeleton especially in forensic application is scarce.

In the present study, growth data of Hemipyrellia ligurriens (Wiedemann) (Diptera: Calliphoridae) were explained based on its cephalopharyngeal skeleton length by using a streamline morphometric analysis. It is a forensically important blowfly species that predominantly colonising corpses in Malaysia and Thailand (Lee et al. 2004; Bunchu et al. 2012; Kumara et al. 2012). Other than charting the cephalopharyngeal skeleton growth, its correlation with the development of larval body length was also determined to show its potential alternative as growth parameter in $\mathrm{PMI}_{\text {min }}$ estimation.

\section{Materials and methods Sample preparation}

This research was conducted in two study replications throughout period from 14 February 2017 to 22 March 2017. Approximately $300 \mathrm{~g}$ decomposed yellowstripe scads (Selaroides leptolepis Cuvier) was used as baits and oviposition medium for adult blow flies. They were placed in a plastic container on the ground and left exposed in outdoor environment adjacent to Forensic Entomology Laboratory, Universiti Kebangsaan Malaysia, Bangi $\left(2.92^{\circ} \mathrm{N}, 101.78^{\circ} \mathrm{E}\right)$. Baits were left exposed for $3 \mathrm{~h}$ to allow oviposition of blow flies and they were frequently checked for any oviposition activity from a single female blow fly. The number of larvae used in this experiment was based on the total number of eggs obtained from a single female blow fly which consists of 87 (study replication 1 ) and 71 eggs (study replication 2), respectively.
The first blow fly egg batch was transferred into a rearing container by using feather forceps. Rearing container consists of $250 \mathrm{ml}$ plastic container with $50 \mathrm{~g}$ fresh cow's liver as food source for the larvae. Liver was placed on $3 \mathrm{~cm}$ layer sawdust and separated by a piece of tissue paper. Eggs were reared at room temperature $\left(23-27{ }^{\circ} \mathrm{C}, 69-94 \% \mathrm{RH}\right)$ overnight. Next day, at $0830 \mathrm{~h}$, newly emerged first instar larvae were transferred evenly into five freshly prepared rearing containers. Larval sampling was conducted twice a day at $0900 \mathrm{~h}$ and $1500 \mathrm{~h}$. During each sampling occasion, three larvae were selected randomly from each container and killed using near-boiling water $\left(\approx 80^{\circ} \mathrm{C}\right)$ (Adams and Hall 2003).

\section{Measurement}

Larval body length was measured in lateral position from the tip of the mouth hook to the posterior spiracle by using Nikon SMZ745T stereomicroscope fitted with Dino-Lite ${ }^{\circ}$ camera and Dino Capture $2.0^{\circ}$ Software.

We obtained cephalopharyngeal skeletons based on guidelines by Rabbani and Zuha (2017). Segment 1-5 of the larvae were cut and soaked in $10 \%$ potassium hydroxide $(\mathrm{KOH})$ for $5 \mathrm{~min}$. Dissected segments were carefully washed in $10 \% \mathrm{KOH}$ to avoid damaging the cephalopharyngeal skeleton structures, and later immersed in $10 \%$ acetic acid for $30 \mathrm{~s}$, followed by immersion in $70 \%$ ethanol for $3 \mathrm{~min}$. Then, cephalopharyngeal skeleton was mounted on a glass slide in lateral position by using Euparal, and covered with $7 \mathrm{~mm}$ rounded cover slip. Cephalopharyngeal skeleton was subsequently measured by using streamline measurement landmarks, i.e., anterodorsal process (clipeal arc) (ADP) to dorsal cornu (DC), ADP to ventral cornu (VC) and DC to VC (Fig. 1) (Nateeworanart et al. 2010; Nuñez and Liria 2016; Rabbani and Zuha 2017).

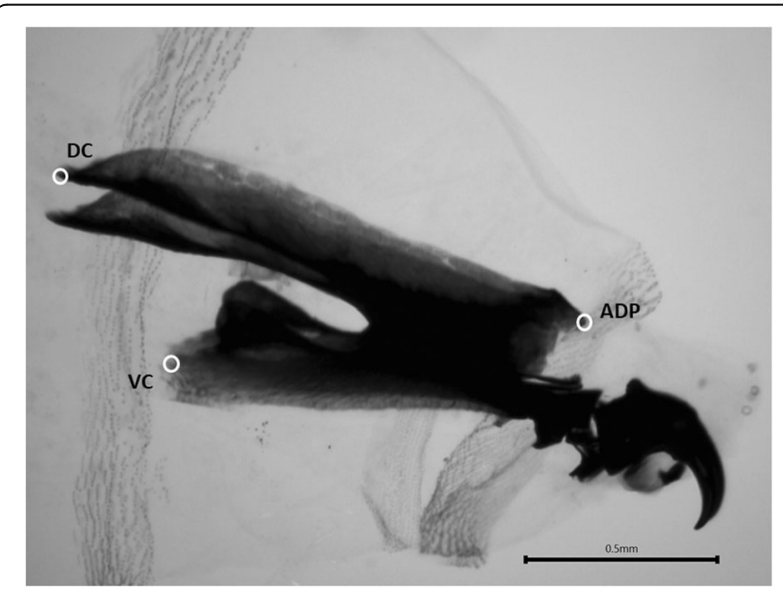

Fig. 1 Developmental landmarks of H. ligurriens based on cephalopharyngeal skeleton length (ADP-DC Anterodorsal process-dorsal cornua, ADP-VC: Anterodorsal process-ventral cornua, DC-VC Dorsal cornua-ventral cornua) $(B a r=0.5 \mathrm{~mm})$ 
Sampling and measurement protocols were repeated in the next sampling and stopped when the larvae reached post feeding stage. Descriptive analysis was carried out to obtain the mean value of the length and within-group sample variance while Spearman's rho correlation test was used to determine correlation between body length and cephalopharyngeal skeleton (ADP-DC, ADP-VC, DC-VC). The statistical tests were performed by using SPSS Ver. 22.0.

\section{Species identification}

Species identifications were conducted on the third instar larvae of the sample and adults that emerged from the remaining larvae colony based on local Calliphoridae identification keys (Kurahashi et al. 1997; Greenberg and Kunich 2002). It was found that all specimens used in this study were H. ligurriens.

\section{Results and discussion}

The development from first instar until peak feeding third instar larvae of $H$. ligurriens took approximately $54 \mathrm{~h}$ in both replications (Fig. 2). Growth patterns based on mean lengths were observed more gradually increased in body lengths compared to mean cephalopharyngeal skeleton lengths. Development of cephalopharyngeal skeletons also exhibited periods of plateau between 0 and $10 \mathrm{~h}$ and 24-30 h (ADP-DC \& ADP-VC) in study replication 1. In study replication 2 , similar patterns were observed in both body lengths and cephalopharyngeal skeleton lengths during the first $10 \mathrm{~h}$, but cephalopharyngeal skeleton lengths reached their plateau stage at $30 \mathrm{~h}$ of development. Overall, the growth pattern of cephalopharnygeal skeleton was coherent with body larval body length in study replication 1 , contrasting the pattern in study replication 2 where the growth of cephalopharyngeal skeleton drastically increased from 24 to $30 \mathrm{~h}$.

The periods of plateau documented in cephalopharyngeal skeletons were possibly existed because of transitional phase during ecdysis, i.e., from first to second instar and from second to third instar. In morphometric studies of larval development, deviations from linear growth suggested instar periods for many species including dipterous larvae (Lawrence 1979; Daly 1985). When compared with data from Bunchu et al. (2012), the pleateau periods of cephalopharyngeal skeleton in study replication 1 could be roughly superimposed on the growth curve of $H$. ligurriens larval stage. This evaluation, however, could be affected by variations of techniques employed in both studies such as rearing temperatures, sample volumes and larval food types. To overcome this issue in future research, it is important to conduct a proper documentation during larval ecdysis by associating the cephalopharyngeal skeleton length with larval instars based on qualitative assessment such as the number of slits in the posterior spiracles (de Carvalho Queiroz et al. 1997; Thyssen and Linhares 2007).

In this present study, larval body length and cephalopharyngeal skeleton length of $H$. ligurriens were further explored by using traditional morphometrics and descriptive analysis (Table 1). Consistencies of measurement values based on body length and cephalopharnygeal skeleton length were represented by within-group sample variance $\left(s^{2}\right)$. In both study replications, variances of ADP-DC, ADP-VC and DC-VC were smaller than variances of body length, indicating that measurements of individual values in cephalopharyngeal skeleton were more consistent than body length. This proved the underlying issues when using larval body length as growth parameter in $\mathrm{PMI}_{\text {min }}$ estimation, that the sclerites of cephalopharyngeal skeleton were more rigid than larval soft bodies which vulnerable to physical distortions. Therefore, in this study, ADP-DC, ADP-VC and $\mathrm{DC}-\mathrm{VC}$ were chosen as the suitable landmarks to represent the cephalopharyngeal skeleton. Previous study included mouth hooks of the cephalopharyngeal skeleton as landmark for measurements, but there were possible drawbacks because they were easily affected by movement during cleaning process, especially in the first and second instar larvae (Rabbani and Zuha 2017). As observed in other calliphorids such as Chrysomya albiceps (Wiedemann) (de Carvalho Queiroz 1997) and Hypopygiopsis fumipennis (Walker) (Heo et al. 2015), different position and shape of mouth hook during different larval instars could also affect the length between landmarks.

In subsequent analysis, correlations between body length and cephalopharyngeal skeleton length of larvae were determined to establish their associations. Since data were not normally distributed, Spearman's rho correlation tests were carried out on body length and cephalopharyngeal skeleton. Results indicate strong significant and positive correlations between body lengths and cephalopharyngeal skeleton lengths which were represented by ADP-DC, ADP-VC and DC-VC for H. ligurriens with correlation coeffiecients, $r$, ranged $0.85-0.97$ $(p<0.05)$ (Table 2). The findings suggested that cephalopharyngeal skeleton allometry can be used as a growth parameter to describe $H$. ligurriens development. Allometric growth patterns in dipterous larvae have been recorded in few developmental studies by highlighting the measurements of cephalopharyngeal skeleton segments, but they were not extended to forensic application (Lawrence 1979; Petitt 1990). Other than being useful in species identification and distinguishing cryptic species (Canal et al. 2015), cephalopharyngeal skeleton of dipterous larvae has been used to describe the growth patterns (Rabbani and Zuha 2017; Simon et al. 2011), but the information is still scarce. It is possible, from the present findings, allometric growth of 


\section{First Replication}
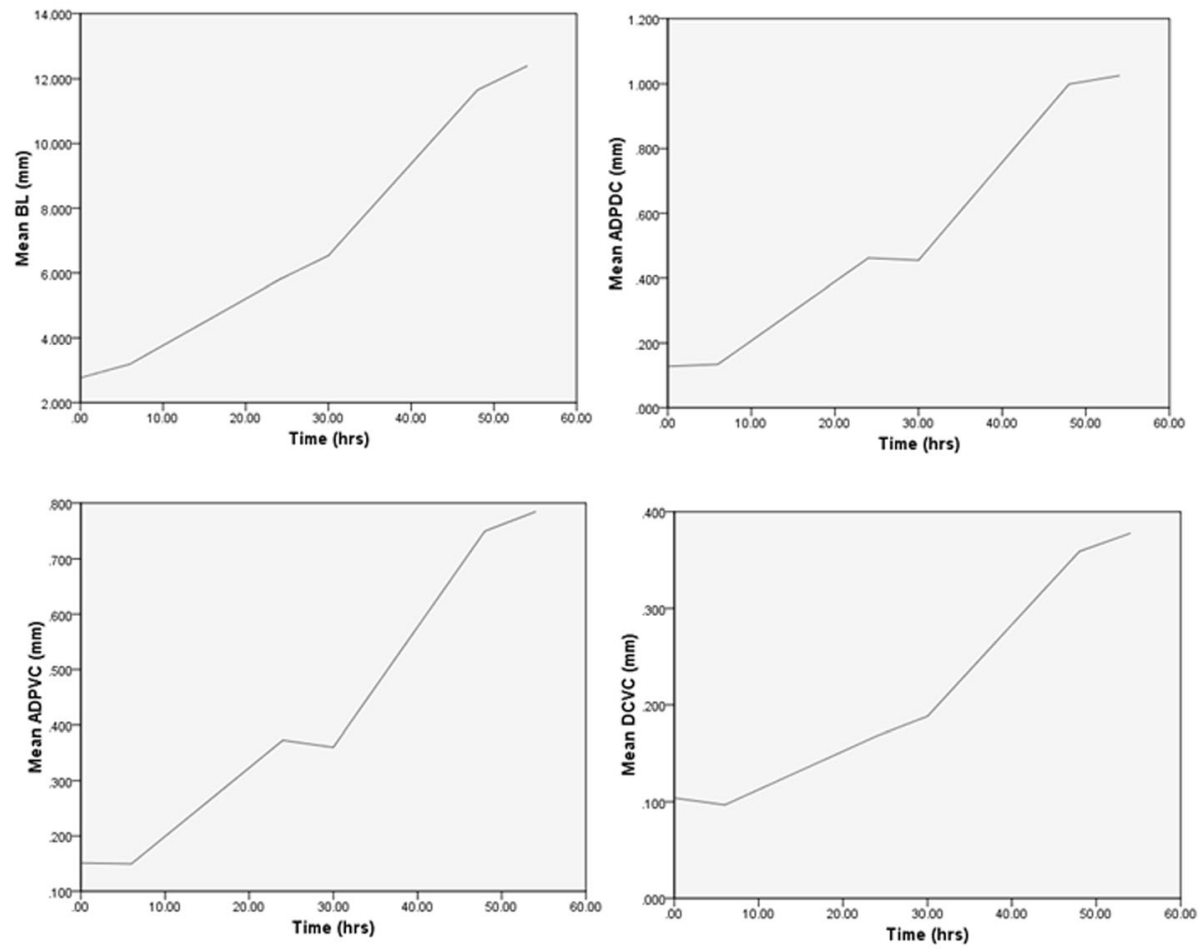

Second Replication
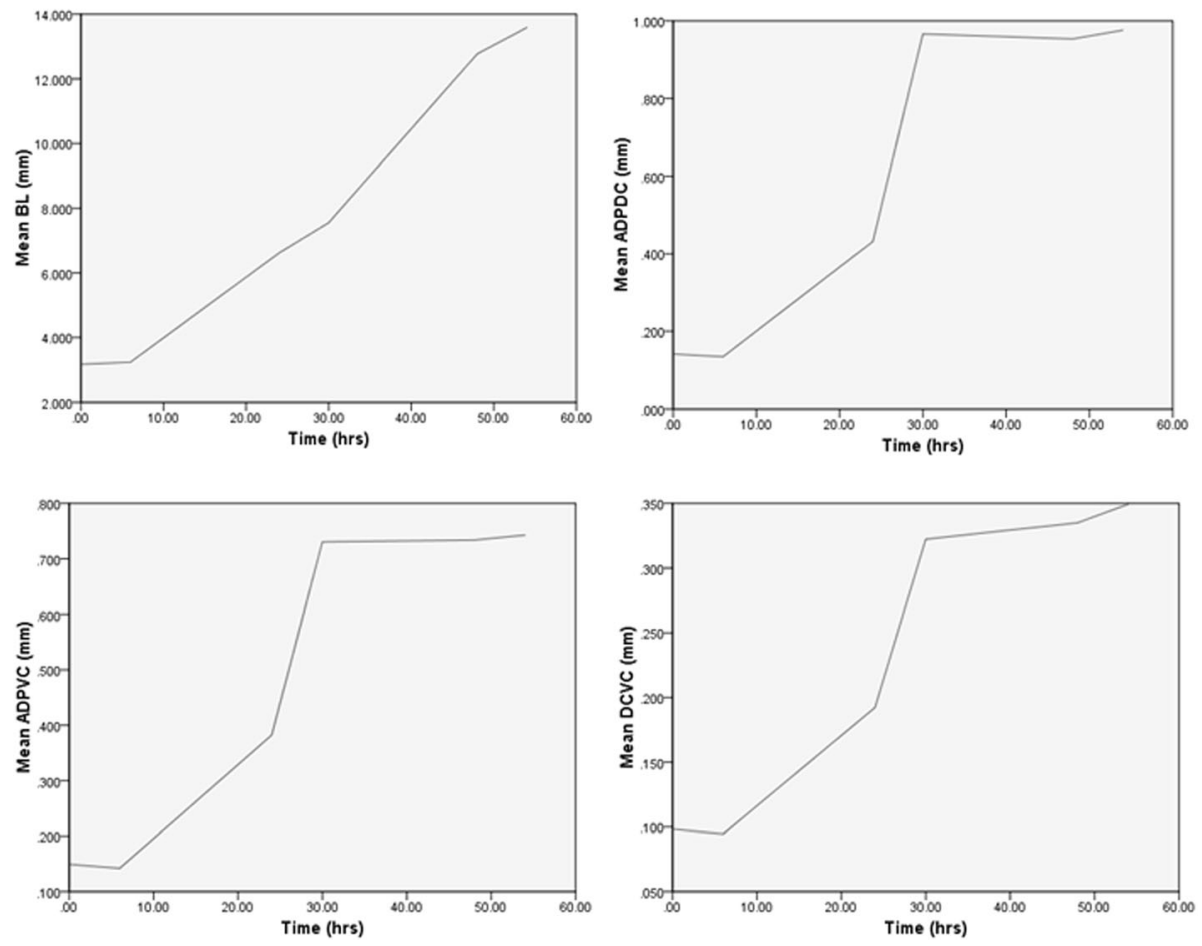

Fig. 2 Developmental rate of larval body length and cephalopharyngeal skeleton (ADP-DC Anterodorsal process-dorsal cornua, ADP-VC Anterodorsal process-ventral cornua, DC-VC Dorsal cornua-ventral cornua) of H. ligurriens in the first and second study replication 


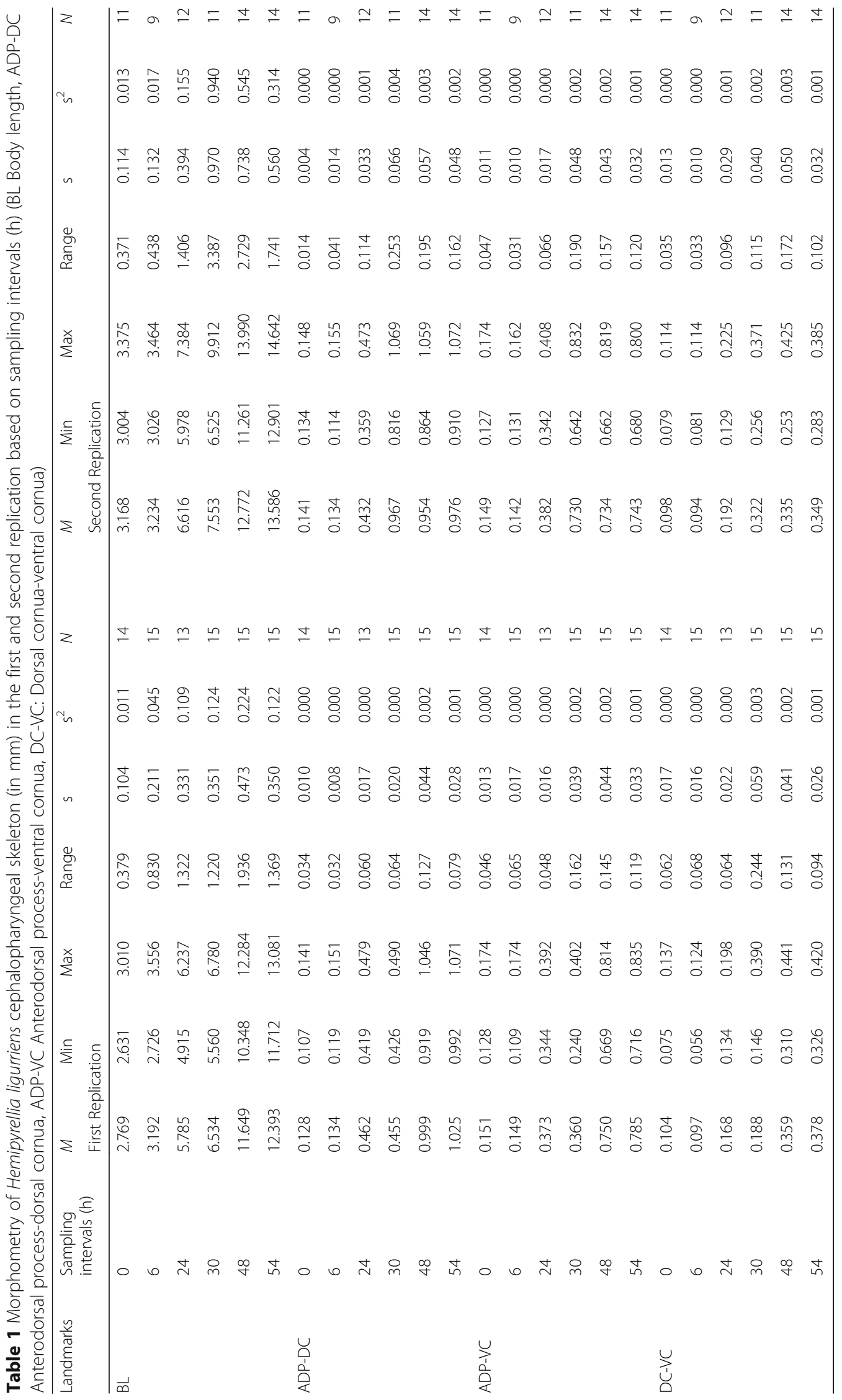


Table 2 Non-parametric correlation analysis using Spearman's rho $(r)$ correlation coefficient and $p$ value of relationships between cephalopharyngeal skeleton and body length of $H$. ligurriens in the first and second replication

\begin{tabular}{|c|c|c|c|c|c|}
\hline Replication & Growth Parameters & $\mathrm{BL}$ & ADP-DC & ADP-VC & DC-VC \\
\hline \multirow[t]{8}{*}{$1 s t$} & $\mathrm{BL}$ & & $r=0.921$ & $r=0.914$ & $r=0.894$ \\
\hline & & & $p<0.05$ & $p<0.05$ & $p<0.05$ \\
\hline & ADP-DC & $r=0.921$ & & $r=0.961$ & $r=0.904$ \\
\hline & & $p<0.05$ & & $p<0.05$ & $p<0.05$ \\
\hline & ADP-VC & $r=0.914$ & $r=0.961$ & & $r=0.901$ \\
\hline & & $p<0.05$ & $p<0.05$ & & $p<0.05$ \\
\hline & DC-VC & $r=0.894$ & $r=0.904$ & $r=0.901$ & \\
\hline & & $p<0.05$ & $p<0.05$ & $p<0.05$ & \\
\hline \multirow[t]{8}{*}{ 2nd } & $B \mathrm{~L}$ & & $r=0.853$ & $r=0.852$ & $r=0.855$ \\
\hline & & & $p<0.05$ & $p<0.05$ & $p<0.05$ \\
\hline & ADP-DC & $r=0.853$ & & $r=0.968$ & $r=0.909$ \\
\hline & & $p<0.05$ & & $p<0.05$ & $p<0.05$ \\
\hline & ADP-VC & $r=0.852$ & $r=0.968$ & & $r=0.898$ \\
\hline & & $p<0.05$ & $p<0.05$ & & $p<0.05$ \\
\hline & DC-VC & $r=0.855$ & $r=0.909$ & $r=0.898$ & \\
\hline & & $p<0.05$ & $p<0.05$ & $p<0.05$ & \\
\hline
\end{tabular}

forensically important larvae could be explored further on its patterns and developmental model.

\section{Conclusions}

These findings demonstrated cephalopharyngeal skeleton as a potential reference to calculate $\mathrm{PMI}_{\text {min }}$ because it proportionally developed with body length. Furthermore, information gathered from this analysis could provide baseline for allometric study or multivariate measurement of size of forensic blow fly larvae as explained in Dyar's rule on the growth of immature arthropods (Klingenberg and Zimmermann 1992; Hutchinson et al. 1997). In forensic practice, cephalopharyngeal skeleton growth data could be so useful if the larval body length could not be obtained due to improper handling of specimens intended for $\mathrm{PMI}_{\min }$ analysis. Therefore, developmental relationships between cephalopharyngeal skeleton and body length certainly merit further investigation.

\section{Abbreviations}

ADP: Anterodorsal process; DC: Dorsal cornu; $\mathrm{KOH}$ : Potassium hydroxide; $\mathrm{PMI}_{\text {min }}$ : Minimum post mortem interval; VC: Ventral cornu

\section{Acknowledgements}

The authors would like to thank all laboratory staffs from Forensic Science Program, School of Diagnostic and Applied Health Sciences, Faculty of Health Sciences, Universiti Kebangsaan Malaysia for providing technical support in this research

\section{Funding}

This research was funded by the School of Diagnostics and Applied Health Science, Faculty of Health Sciences, Universiti Kebangsaan Malaysia.
Equipment used is this research was partially funded by the second author's Young Researcher's Incentive Scheme (Geran Galakan Penyelidik Muda) GGPM-2014-018.

\section{Availability of data and materials}

Data is available by request to the corresponding author: rmzuha@ukm.edu.my.

\section{Authors' contributions}

PE and RMZ conducted the research and organised the structure of the manuscript. Both authors read and approved the final manuscript.

\section{Authors' information}

PE was an undergraduate student and supervised by RMZ, the project leader and a forensic entomology consultant at Universiti Kebangsaan Malaysia (UKM). RMZ is currently attached to UKM Forensics and a researcher at Center for Insect Systematics, UKM.

Ethics approval and consent to participate

Not applicable.

\section{Competing interests}

The authors declare that they have no competing interests.

\section{Publisher's Note}

Springer Nature remains neutral with regard to jurisdictional claims in published maps and institutional affiliations.

Received: 28 November 2017 Accepted: 1 June 2018

Published online: 06 June 2018

\section{References}

Adams ZJO, Hall MJR (2003) Methods used for the killing and preservation of blowfly larvae, and their effect on post-mortem larval length. Forensic Sci Int 138:50-61. https://doi.org/10.1016/j.forsciint.2003.08.010.

Amendt J, Campobasso CP, Gaudry E, Reiter C, LeBlanc HN, Hall MJR (2007) Best practice in forensic entomology — standards and guidelines. Int J Legal Med 121:90-104.

Amendt J, Richards CS, Campobasso CP, Zehner R, Hall MJR (2011) Forensic entomology: applications and limitations. Forensic Sci Med Pathol 7(4):379392. https://doi.org/10.1007/s12024-010-9209-2.

Bookstein FL (1982) Foundation of morphometrics. Annu Rev Ecol Syst 13:451470. https://doi.org/10.1146/annurev.es.13.110182.002315.

Bunchu N, Thaipakdee C, Vitta A, Sanit S, Sukontason K, Sukontason KL (2012) Morphology and developmental rate of the blow fly, Hemipyrellia ligurriens (Diptera: Calliphoridae): forensic entomology applications. J Parasitol Res:110. https://doi.org/10.1155/2012/371243.

Byrd JH, Castner JL (2010) Forensic entomology: the utility of arthropods in legal investigations. CRC Press, Boca Raton.

Canal NA, Hernandez-Ortiz V, Tigrero Salas JO, Selivon D (2015) Morphometric study of third-instar larvae from five morphotypes of the Anaestrepha fraterculus cryptic species complex (Diptera, Tephritidae). ZooKeys 540:41-59.

de Carvalho Queiroz MM, de Mello RP, Lima MM (1997) Morphological aspects of the larval instars of Chrysomya albiceps (Diptera, Calliphoridae) reared in the laboratory. Mem Inst Oswaldo Cruz 92(2):187-196.

Daly HV (1985) Insect morphometrics. Annu Rev Entomol 30:415-438.

Day DM, Wallman JF (2006) Width as an alternative measurement to length for post-mortem interval estimations using Calliphora augur (Diptera: Calliphoridae) larvae. Forensic Sci Int 159(2-3):158-167. https://doi.org/10. 1016/j.forsciint.2005.07.009.

Day DM, Wallman JF (2008) Effect of preservative solutions on preservation of Calliphora augur and Lucilia cuprina larvae (Diptera: Calliphoridae) with implications for post-mortem interval estimates. Forensic Sci Int 179(1):1-10. https://doi.org/10.1016/j.forsciint.2008.04.006.

Greenberg B, Kunich JC (2002) Entomology and the law: flies as forensic indicators. Cambridge University Press, Cambridge.

Heo CC, Latif B, Silahuddin SA, Nazni WA, Omar B (2015) Morphological descriptions on the larvae of Hypopygiopsis fumipennis (Walker, 1856) (Diptera: Calliphoridae). Trop Biomed 32(1):151-159.

Hutchinson JMC, McNamara JM, Houston Al, Vollrath F (1997) Dyar 's rule and the investment Principle : optimal moulting strategies if feeding rate is size- 
dependent and growth is discontinuous. Philos Trans R Soc London Ser B Biol Sci 352:113-138. https://doi.org/10.1098/rstb.1997.0007.

James Rohlf F, Marcus LF (1993) A revolution in morphometrics. Trends Ecol Evol 8(4):129-132.

Klingenberg CP, Zimmermann M (1992) Dyar's rule and multivariate allometric growth in nine species of waterstriders (Heteroptera: Gerridae). J Zool 227: 453-464. https://doi.org/10.1111/j.1469-7998.1992.tb04406.x.

Kumara TK, Disney RHL, Hassan AA, Flores M, Hwa TS, Mohamed Z, Chesalmah MR, Bhupinder S (2012) Occurrence of oriental flies associated with indoor and outdoor human remains in the tropical climate of North Malaysia. J Vector Ecol 37(1):62-68. https://doi.org/10.1111/j.1948-7134.2012.00200.x.

Kurahashi H, Benjaphong N, Omar B (1997) Blow flies (Insecta: Diptera: Calliphoridae) of Malaysia and Singapore. Raffles Bull Zool Supp No.5:1-88.

Lawrence PO (1979) Immature stages of the Caribbean fruit fly, Anastrepha suspensa. FlaEntomol 62(3):214-219.

Lee HL, Krishnasamy M, Abdullah AG, Jeffery J (2004) Review of forensically important entomological specimens in the period of 1972-2002. Trop Biomed 21(2):63-69.

Marcus LF (1988) Chapter 4 traditional morphometrics. In: Rohlf FJ, Bookstein FL (eds) Proceedings of the Michigan Morphometrics workshop. The University of Michigan Museum of Zoology, Michigan, pp 77-122.

Midgley JM, Villet MH (2009) Effect of the killing method on post-mortem change in length of larvae of Thanatophilus micans (Fabricius 1794) (Coleoptera: Silphidae) stored in 70\% ethanol. Int J Legal Med 123(4):103108. https://doi.org/10.1007/s00414-008-0260-4.

Nateeworanart S, Bunchu N, Vitta A (2010) Cephalopharyngeal skeleton measurement of Chrysomya megacephala, third instar larvae, collected from Naresuan University, Phitsanuk Province. J Med Technol Assoc Thail 38(1): 3100-3105

Nuñez JA, Liria J (2016) Cephalopharyngeal geometric morphometrics in three blowfly species (Diptera: Calliphoridae). J Entomol Zool Stud 4(1):338-341.

Nuñez-Rodríguez JA, Liria J (2017) Geometric morphometrics sexual dimporhism in three forensically-important species of blow fly (Diptera: Calliphoridae). Life Excit Biol 4(4):272-284.

Petitt FL (1990) Distinguishing larval instars of the vegetable leafminer, Liriomyza sativae (Diptera: Agromyzidae). Fla Entomol 73(2):280-286.

Rabbani A, Zuha RM (2017) Cephalopharyngeal skeleton morphometry of Hypopygiopsis violacea (Macquart) (Diptera :Calliphoridae) - a preliminary assessment for its application in forensic entomology. J Entomol Zool Stud 5(1):777-782

Richards CS, Rowlinson CC, Hall MJR (2013) Effects of storage temperature on the change in size of Calliphora vicina larvae during preservation in $80 \%$ ethanol. Int J Legal Med 127:231-241.

Rosilawati R, Omar B, Syamsa RA, Lee HL, Nazni WA (2014) Effects of preservatives and killing methods on morphological features of a forensic fly, Chrysomya megacephala (Fabricius, 1794) larva. Trop Biomed 31(4):785-791.

Simon PP, Krüger RF, Ribeiro PB (2011) Influence of diets on the rearing of predatory flies of housefly larvae. Arq Bras Med Vet Zootec 63(6):1414-1420.

Strauss RE, Bookstein FL (1982) The truss: body form reconstruction in morphometrics. Syst Zool 31(2):113-135. https://doi.org/10.2307/2413032.

Tantawi Tl, Greenberg B (1993) The effect of killing and preservative solutions on estimates of maggot age in forensic cases. J Forensic Sci 38(3):702-707.

Thyssen PJ, Linhares AX (2007) First description of the immature stages of Hemilucilia segmentaria (Diptera: Calliphoridae). Biol Res 40:271-280.

Wells JD, LaMotte LR (1995) Estimating maggot age from weight using inverse prediction. J Forensic Sci 40(4):585-590.

Zelditch ML, Swiderski DL, Sheets HD, Fink WL (2012) Geometric morphometrics for biologists-a primer, 2nd edn. Academic Press, London.

\section{Submit your manuscript to a SpringerOpen ${ }^{\circ}$ journal and benefit from:}

- Convenient online submission

- Rigorous peer review

- Open access: articles freely available online

- High visibility within the field

- Retaining the copyright to your article

Submit your next manuscript at $\gg$ springeropen.com 